DE DE GRUYTER OPEN
Journal of Intercultural Management

Vol. 5, No. 3, September 2013, pp. 49-61

DOI 10.2478/joim-2013-0018

Grzegorz Mazurkiewicz

Jagiellonian University

John M. Fischer

Bowling Green State University

\title{
Crossing the frontiers. \\ Peer coaching and self-managing in the process of the professional development in multicultural environment
}

\begin{abstract}
Our effort focuses on the development of a process of cross-cultural peer coaching through which we have sought to grow as reflective practitioners and strengthen authentic conversations between two individuals, from Poland and the United States. By building a theoretical framework around peer coaching, intercultural interaction, and auto-ethnography we have worked to make explicit our development as educators working to enrich the process of the organizational learning and to make education more open, democratic and human. As Kottler [1997] claims, it is possible to find stages that a tourist goes through during the process of recognizing and knowing another culture that was used to mirror the sensation of the professional growth. The findings shed light on how peer coaching might be strengthened, as well as the development of an observation protocol to structure such reflective and, ultimately, life changing work.
\end{abstract}

Key words: Peer coaching, professional development, intercultural interactions

\section{Introduction}

Starting from the conviction that organizational learning starts with individuals' learning and personal mastery we have tried to describe and to understand the professional development process that we had participated in. This paper describes our effort to develop a process through which we have 
sought to become mature teachers, develop as reflective practitioners and strengthen authentic conversations between authors: two individuals working at universities in Poland and the United States. By building a theoretical framework around peer coaching, intercultural interaction, and autoethnography we have worked to make explicit our development as professors, teachers and educators.

The authors have been involved in a professional dialogue for years. When a chance appeared we agreed to visit each other's classrooms for two semesters and try to help ourselves in the professional growth that eventually should impact also organizations, which we were working for. The basic question for development efforts of individuals within organizations should focus (besides needed competencies) on increasing the feeling of the ownership, belonging and responsibility. Through description of our professional development and analyses of it within the framework of intercultural relations we wanted to present the stages of every professional development initiative (with a special focus on initiatives in multicultural environment).

We want to stress the belief that modern and successful organization should search for ways of supporting the participatory management within its structures and should accept that people are free and it is more important to focus on their potential than on their deficits. We agree that participation is connected to professional development and also arises from balance between responsibility of employees and relations within group. To participate we need to understand the situation and be motivated to be a part of it [Stocki, Prokopowicz, Żmuda, 2008]. Only authentic and critical reflection leads us to that level of professional maturity.

We decided that we will focus on two critical issues. First, our ability to create an open and democratic classroom during our daily practice and second, on our professional dialogue in the form of peer coaching method.

\section{Framework for study's methodology}

Peer Coaching

Peer coaching is the process of helping people enhance or improve their performance through reflection on how they apply a specific skill or knowledge [Clifford, Thorpe, 2007]. It is a strategy for educators to consult with one another, to discuss and share teaching practices, to observe classes, to promote collegiality and support, and to help ensure quality teaching for all students. The relationship is built on confidentiality and trust in a non-threatening, secure environment in which they learn and grow together [ASCD, 2007].

It is targeted to meet individual needs [Clifford, Thorpe, 2007]. It is designed to improve teaching through feedback, support, and assistance that allows 
refining present skills, learning new skills, and/or solving classroom-related problems [Dalton and Moir, 1991]. One of the models describe five functions of successful teachers' peer coaching that we tried to address:

- Companionship: Teachers talk about their successes and failures reducing their sense of isolation;

- Feedback: Teachers give each other objectives, non-evaluative feedback about the way they are executing skills;

- Analysis: Teachers help each other extend their control over a new approach until it is internalized, spontaneous, and flexible;

- Adaptation: Teachers work together to fit a teaching model to the special needs of students in the class; and

- Support: The coach provides whatever support is needed [Showers, 1984].

The process of critical reflection might be inspired and enriched by the discussion with another professional. In that way the process of learning and developing is a process of social construction of meanings and understanding, and in our case the process of constructing knowledge about teaching and learning.

Structure for the coaching process and observation

We agreed that we needed a structure of the peer coaching process in order to focus our attention on the most important issues. We created an observation protocol that tries to document how our behavior influences students' involvement in the classroom. We created an observation sheet that helped us to frame the process of observation, and provided us with notes that could be used to structure debriefing discussions afterwards.

Each peer coaching session began with the peer attending the class in order to collect observations. These observations were focused using a frame centered on a key question of how an instructor's actions worked to involve and engage students in the class. The data collected during observation served as support for the peer coaching discussions. In those discussions we trusted each other what is a crucial factor in the success of peer reflection. Nobody is able to reach for deep and useful insight in a situation in which more important than somebody's personal development is their sense of security and their professional image [York-Barr, et. all, 2001, p. 23].

All our coaching sessions created space for analyses on two levels. First, was the procedural level, which allowed us to improve our practice and let us reflect on how we work and how to improve it. Second, was the theoretical level, that inspired us while visiting our classrooms to think about what we were observing in a much broader sense of educational philosophy and the development of democratic educational environments. 


\section{Interdisciplinary Reflection}

While we were thinking about our experience during these peer coaching activities we came to understand that we could use the metaphor of tourist ${ }^{1}$ to explain our role in the other person's classroom (reality, culture, world). The sensations that we experienced during visits in each other's classroom were similar to those that we feel when we travel to another land. This similarity brought numerous questions that enriched our peer coaching relationship, about: host and hospitality, responsible traveler, and the images and stereotypes that we look for. It appeared that two semesters of peer coaching allowed us to see ourselves through different lenses, to question our beliefs and habits, to think deeply about the relationship with student, subject and teaching process.

Being aware how multidirectional might be a process of the professional development we tried to implement a multidisciplinary approach in our selfinquiry. To build a sense of multiple perspectives in education we used Kottler's approach to cross-cultural meeting, contact and work. We were trying to refer to that cycle in all our attempts to understand situations in our classrooms and, what is critical here, the dynamic of our relationship as peer coaches. We suggest that these two human activities: travelling and visiting classrooms for coaching purposes are similarly structured and paced.

Stages of Travel

Kottler [1997] described the process of adjustment to another culture during travel ${ }^{2}$. It is possible to find five stages that a tourist goes through during the process of recognizing and knowing another culture. We decided to use it for thinking about us, in our classrooms, as a structure enabling understanding our emotions and behavior:

1. The stage of recognizing. In this moment we are excited and confused. Colors, places, smells, tastes, people, faces, food make us happy and almost unconscious.

2. The stage of irritation. Created by cultural shock, when the new experiences do not cause joy or astonishment but anger and depression what may lead to an emotional crisis and aggression.

3. The stage of adjustment. Negative feelings become weaker and we are able to act according to rules within certain cultures.

4. The stage of reflection. We compare values and beliefs, behaviors and

1 We understand the controversy around that term but we decided to use it and to think about the person who travels rather than the person who is sent on a "package" tour to a chain hotel in a walled in resort.

2 The similar issue was a point of discussion in G.V. Doxey: A Causation Theory of Visitor-Resident Irritants. Methodology and Research Inferences. The Impact of Tourism. Sixth Annual Conference Proceedings of the Research Association, San Diego 1975, s. 195-198. 
customs, usually we have to make a painful evaluation of our own culture. In other words, it is a process of acceptance.

5. The stage of adaptation. If we are in certain cultural frames long enough we are able to reach the stage of adaptation.

We were hoping that the theory and practice of peer coaching enriched by a perspective of the intercultural communication would allow us to take off a pressure from the process of being observed and judged.

\section{Theoretical context and beliefs}

To become a teacher it takes much more than tolearn how to pass information, introduce new skills or implement appropriate teaching techniques. The process of becoming 'A Teacher' includes a complex process of building understanding of the world, developing respect and awareness of students as human beings, and reflection on individual development. It takes time and courage to open minds and hearts for creating relationships based on mutual recognition.

The professional development of teachers needs to enrich their vision of their role in the classroom and support the conviction that it is crucial for every student to be active and heard [Freire, 2001]. Unfortunately existing practice within formal systems of schooling brings threat and fear into our classroom [Harber, 2004; Palmer, 1998] something that is difficult to overcome with traditional means of school improvement and reforms. We need new kinds of teachers with new approaches to teaching, learning and students. bell hooks [1994] writes about engaged pedagogy demanding from teachers involvement in a process of self-actualization that promotes their own well-being, something which enables teaching in a manner that empowers students and allows the experience of education as the practice of freedom [Freire, 2001, Ayers, 2004].

How to build a learning process for teachers that would allow them to notice connections between life practices, habits of being and the roles of educators? Unfortunately the idea of the intellectual questing for a union of mind, body and spirit through education had been replaced with the notion that being a smart and good teacher means being able to survive in the classroom [hooks, 1994].

Teachers need to build respect for the autonomy of the learner [Freire, 2001, p. 59, Shor, 1992] and this respect might be developed through mutual relations with others in an atmosphere of understanding, openness and tolerance. It is extremely difficult to build and maintain this atmosphere especially for those who are "products" of closed and anxious societies governed by hidden rules that hurt numerous "invisible" groups and minorities [Bauman, 2005]. One of the possible directions in the change of teachers' and professors' professional development initiatives might be increasing their peer interactions. Our tendency to reduce teaching to questions of techniques is one reason we lack 
conversation and professional reflection [Palmer, 1998]. We need to create opportunities for deliberation about critical moments in our lives and in our teaching that will use both: metaphors and real life examples. We need to create opportunities for observing each other's teaching, not only through reports or students' surveys but also by watching other teachers work in classrooms [Day, 2008 , p. 165]. We need to create a community of learners that would start a common journey to developing better teachers and trust. Trust ties us together in learning communities [Sztompka, 2007]. Teachers build or diminish the amount of trust in the world. Coming to trust another person is the most fragile of human projects. It requires knowing someone over a period of time and seeing their honesty modeled in their action [Brookfield, 1995].

\section{Findings: searching for things to borrow and lend}

By working to debate and define the key evidence of each stage we came to a clearer understanding of each others cultural and classroom context and practices.

Traveling to a Different Land: Entering Another's Classroom

We believed we were working to make our classrooms more democratic what should be visible through: space for multiple perspectives, multiple voices, shared power relationships and focus on the construction of knowledge. Grzegorz began teaching a course on action research and the first class was like meeting a stranger in the foreign country. Maybe it is the same for every teacher everywhere. When we meet our students we are excited and do not know that will happen.

The main concerns about the class at the very beginning were very general in nature. Thanks to the debriefing conversation after class we were able to think about more specific issues. Both approaches: very general, connected to a value system and very specific, connected to the teacher's behavior helped to increase understanding of this that was seen. Our debriefing discussions after class often were echoed in logs.

Grzegorz: I left too short time for their introduction. I need to remember about not monopolizing the whole space during the class. It is obvious that they are not sure what to think about me.

When traveling, the stage of recognition is the first we encounter. This was true for everybody involved in this class and in this process. We became quickly aware that we were going through this stage.

At the same time, John began his "normal" fall schedule of undergraduate classes with students studying to become Social Studies teachers. The first visit and observation in John's class left Grzegorz with the impression of a 
good climate, friendly relations with students and the idea that everyone in this class is seen and cared about. There were significant differences between John and Grzegorz's class. In John's class participants and the teacher were less concerned about what they participated in, less fear of the unknown. And yet something was similar - only a smaller, identifiable group of students actively participated in the class discussion.

John: ...The presence of a peer in the classroom does seem to alter what I do. I spent more time on the debriefing than normal (he even said I should have spent more). I do find myself more concerned about my communication when he is here.

It took a while but we came to realize that Kottler's [1997] stages are a permanent element of almost every human relationship. That although one may go through the whole cycle and adjust to new culture this process inevitably will happen again when there will be conditions for this. Agreeing with this statement leads us to conclusions that every classroom will go through those stages regularly in the spiral of cycles influenced by age, moment of the school year, demographic of the class.

From recognition to irritation

Grzegorz: Discussion with students about observations, findings and conclusions was interesting and eye opening. I could see that they understood why I asked them to do it. ...I am not sure how can I help in the process of the problem formulation. Now they understand what this is, but it looks that they are overwhelmed. I am afraid that I am loosing my contact with them, because they avoid honest declaration about their struggle.

During the debriefing session John mentioned how obvious their body language was when Grzegorz talked about their fears - they were silent and withdrawn. It was visible that it is difficult also for Grzegorz - the supportive content and openness in this speech were in opposition to style of the communication. John noticed that Grzegorz was in a different place, standing and speaking with different tone than usual. It was a critical moment. From that point the relationship in this class became easier.

\section{Adjustment and Reflection}

In an invisible way through the process of irritation we moved slowly to stage of adjustment and reflection. During conversation with John, Grzegorz found out that John believes that there was a significant problem created by Grzegorz's communication style and intercultural misunderstanding. The peer coaching session raised doubts. 
Grzegorz: I am not sure if it is a "real thing" or something created by our conversations. If I would not know it would it be easier or not? I feel that I am going through frustration phase again. I need to do something different in the next class.

Over the course of the semester we did not always agree with each other, we did however raise issues, debate philosophies, argue strategies, furniture, position in the class and yes, even dress. What does it take to create a democratic classroom, with active participants who feel challenged and yet supported in their aim to learn?

The Cycle of Travel begins Again...

A year later, John arrived in Poland. He was nervous. He was aware of his lack of real knowledge about the students' program of study and unsure of what to expect as he proceeded to craft two syllabi for classes at the university. John chose to focus on issues related to school reform in different parts of the world.

John: We worked on education definitions. ...I then introduced bell hook's piece. At the end I tried to have a discussion-although there was a lot of silence. I decided to try and see how long the wait time of the group would be. Who would wait whom out? I am not sure who won...

Suddenly, Grzegorz had understood that relationship between John and him had changed direction. He became a host, a person "responsible" for failure or success of John's teaching in Poland and also for well-being of John (and his students too). Everything that was easy to struggle when it was Grzegorz who struggled became difficult when it was John who supposed to overcome: bureaucracy at university, housing arrangements, shopping without knowing language and the most important relations with students.

\section{Irritation}

Teaching together and visiting each other's classes created new phenomenon - we were so focused on the practice of our teaching that thinking about it started to be "disturbing". We became aware and self-reflective but also selforiented, more interested in analyzing ourselves than students' learning.

When we realized that, it struck us in a very unpleasant way - our irritation rose from our own actions. So, we tried to be better teachers through peer coaching and reflection but we lost (for a moment) our students in that process.

Adjustment

After moments of doubts when we saw how deeply we were involved in selfevaluation while loosing sight of student benefits, we moved to the next stage in our teaching - we increased the level of trust we had in them (again). 
John: On that day they were really ready. Many had things to read, everybody spoke... The power points were on target and they had synthesized the articles down to their essence. It was clear they had worked...

Grzegorz next spoke and slammed them on presentation style... and not one positive comment... I feel much more appropriate giving comments on drafts and their work in progress.

Grzegorz: When does teaching, understood also as giving feedback, stop? Today I watched John's class presenting their mid-term projects, they did quite good job but their presentations were not the best - all of them had some minor mistakes. When I decided to point some of them John was not glad and this brought this question to me: when does teaching stop? John saw it as irrational criticism coming from Polish culture and tradition.

\section{Adaptation}

It was obvious for us that we are more and more confident in our capacity to cooperate and to teach. Moments of potential conflicts, (like different styles of communication with students) did not bring anxiety anymore but rather new perspectives, new contexts of classwork.

John: In the course that we taught together which started later during semester, we had a syllabus in place that we hoped would flow in a conceptual manner from education to globalization to democracy to leadership. First class began by having them 'interview' each other. Their interview sharing was interrupted by Grzegorz asking clarifying questions, pointing out themes and also sharing his impressions. It was interesting to watch that Grzegorz is more aggressive "so, what did you hear, tell us again" appeared to really show that we were listening and wanted them to listen.

\section{Stage of Reflection}

One of the most important benefits of our cooperation was the time of common reflection, a luxury that usually teachers do not have in their professional life [Yero, 2002]. This lack of the reflection might be caused by different reasons: deficits of time, preparation and training, awareness or need, understanding of the role of reflection in the development of human beings.

What does it mean to teach? It is learning about others and yourself. It is creating an understanding of points of view, places of departure, different goals and needs, various levels of being here. Teaching is an awareness of the diversity and of the learners' freedom - freedom of choice of the career path, of the course or of the level of participation in the class. Teaching is a process of thinking about others and about us in that way that allows different points of view. The metaphor of playing jazz in a band of the great musicians comes to 
our minds when we think about good teaching and learning process - we keep the rhythm, we enjoy playing together, we are going with the melody and from time to time we share responsibility - when it is time to do it those musicians who feel like it play a solo, enriching our performance.

\section{Conclusions}

Negotiating from Tourist to Member of the Learning Community

Quality of teaching and learning depends on communication styles, teacher student interaction, language issues, moving beyond surface level and more. As we traveled in and out of each other's classrooms and countries we felt again and again these travelers' companions: frustration, recognition, adjustment, reflection and adaptation. Thinking about visits in classroom as about an "exotic" journey helped us to develop more open attitude and approach enabling learning instead of evaluating.

How might we structure such experiences for others? What might be done to achieve the goal of a well constructed, well-developed professional development process for teachers and education for all students? When we think about successful professional development through peer coaching there are few conditions that should be secured for the benefits of the process.

Firstly, peer coaching implies equality. Even when there is a possibility of different experiences or different levels of education all actors involved in the process have to represent honest attitudes and readiness to be treated in the exactly same way.

Secondly, the input of the real work has to be similar on all sides involved of in the process. Collaborative work helps to make it more authentic and rewarding. It cannot be done by someone and used by others.

Thirdly, as educators we need a professional development process to be continuous and ongoing. If we are to improve this process, it must become a habit of mind, more permanent and more ongoing.

Three conditions do not create a closed list of factors enabling teachers' transformation into members of the learning community but may make it more possible. As tourist, through authentic involvement, respect and understanding, might become a valuable member of the local community instead being annoying external visitor, so teacher instead being detached "expert" might share learning experience with all involved.

Reflecting on teaching

We learned a lot about our teaching. It is difficult to describe something that appeared as an emotional, hard to grasp definition, that is flexible as a liquid - our approach to teaching. This process of growing served as one step in a movement toward self-actualization. 
We have understood that personal feelings and deep understanding of very personal issues are more important for our teaching (and learning) than technical procedures or methodological tools. We realized that we needed theory as a platform on which we built our teaching not as an abstract idea. We realized that we need methods to check, discuss and criticize them in order to build our personalized approach to teaching. We realized that we needed our peer to hold a mirror for us in which we could see our mistakes, failures and successes and to support us with discussion that deepened the ability to teach.

It is possible to draw a scheme with three areas determining our teaching style, effectiveness and professional development.

First area is an understanding of the teacher's role and aims of teaching. We do not want to tell how it should look, but we are saying that in the process of professional development, using the model of peer coaching, it is inevitable to create a ground that enables peers to discuss these issues. Without understanding of our personal beliefs that exist with our pedagogical assumptions it is impossible to develop and to teach. For us it appeared that we see teaching as guiding others, so we really need to focus our attention on students and the relationship with them. Focusing too much on the act of teaching may, instead, disturb learning.

Second area is our ability to interact with our students, our peers and the world. Interaction means meeting the other and the difference. As teachers we need to be able to do it appropriately - we need to prepare ourselves for dialogue with others even if it is frustrating and not comfortable. Communication styles are different but it does not mean that we cannot communicate. Without that skill, teaching and learning will not happen. For us it was obvious that we are allowed to feel anxiety and frustration, but we were able to transform it into strength. When teachers feel uncomfortable they do what students (who also fear the classroom reality) expect (or what they think students would expect).

Third area is our ability to manage and facilitate the process of learning with different approaches, methods and techniques. We need to be ready to teach every student and to work with every teacher, so our resources in this matter should be really broad. The ability to flexibly use different approaches creates and supports a democratic environment. It is the teacher's responsibility to solve potential problems in cooperation with students and teachers' professional background helps them to do it. This responsibility brings on anxiety, anxiety that might be healed if we work in all three of those areas.

How do we strengthen professional development models such as peer coaching? Our experience over the last two years shows that structured, but contextual models can work. Teachers need to enrich their vision of their role in the classroom as Freire [2001] said and develop classrooms and educational 
environments where students are active and have voice. Teachers must become more self aware and conscious of their possibilities and responsibility to make educational settings more humane and democratic and less threatening for students [Harber, 2004; Palmer, 1998; bell hooks, 1994]. Our travel allowed us to see more questions than answers. Questions about the value of change, about the quality of education and the quality of teaching as a universal and unique value, and about decision-making process. You cannot be a teacher if you do not ask these questions.

Reflecting on professional development as organizational learning

Every initiative of the professional development brings change, both for participating individuals and their organizations. This is a dynamic process that change work conditions and attitudes of the employees. That process conducted in the multicultural environment demands openness and readiness for constant adjustments of the behaviors and procedures. There are no chances for safe functioning in well-known and stable environment but rather promise of rapid changes of emotions, ideas, decisions and directions but in very creative atmosphere.

The only conditions of success is acceptance of the processes we are going through and securing time for growth while passing the inevitable stages of the development process. Using metaphor of border crossing it is useful to remember that guards are usually slow and very careful in their checking procedures - it is impossible to skip it and jump forward in the line. The same is true in the professional development.

\section{Bibliography}

Association for Supervision and Curriculum Development (2007), Peer coaching, [Online], Available: http://webserver3.ascd.org/ossd/peercoaching.html [1 June 2010].

Ayers, W. (2004) Teaching Toward Freedom. Moral Commitment and Ethical Action in the Classroom, Boston: Beacon Press.

Bauman, Z. (2005), Życie na przemiał, Kraków: Wydawnictwo Literackie.

Brookfield, S.D. (1995) Becoming a critically reflective teacher, San Francisco: JosseyBass.

Clifford, J., Thorpe, S. (2007) Workplace Learning and Development. Delivering Competitive Advantage for Your Organization, London and Philadelphia: Kogan Page.

Dalton, S. and Moir, E. (1991) Evaluating LEP teacher training and in-service programs, Paper presented at the Second National Research Symposium on Limited English Proficient Student Issues. Washington, DC. 
Darder, A (2002) Reinventing Paolo Freire: A Pedagogy of Love, Colorado: Westview Press.

Day, C. (2008) Nauczyciel z pasją. Jak zachować entuzjazm i zaangażowanie w pracy, Gdańsk: Gdańskie Wydawnictwo Psychologiczne, Biblioteka Wychowawcy.

Dewey, J. (1916) Democracy and education: An Introduction to the Philosophy of Education, New York: Free Press.

Doxey, G.V. (1975) A Causation Theory of Visitor-Resident Irritants. Methodology and Research Inferences. The Impact of Tourism, Sixth Annual Conference Proceedings of the Research Association, San Diego.

Freire, P. (2001) Pedagogy of Freedom. Ethics, Democracy and Civic Courage, Boulder, New York, London: Rowan and Littlefield Publishers, Inc.

Harber, C. (2004) Schooling as violence. How schools harm pupils and societies, London and New York: RoutledgeFalmer Taylor \& Francis Group.

hooks, b. (1994) Teaching to Transgress: Education as the Practice of Freedom, London: Routledge.

Kottler, J.A. (1997) Travel that can change your life: How to create a transformative experience, San Francisco: Jossey-Bass Publishers.

Parker J. P. (1998) The Courage to Teach. Exploring the Inner Landscape of a Teachers' Life, San Francisco: Jossey-Bass Publishers

Shor, I. (1992) Empowering Education. Critical Teaching for Social Change, Chicago and London: The University of Chicago Press.

Showers, B. (1984) Peer Coaching: Strategy for Facilitating Transfer of Training, Eugene, Ore.: Center for Educational Policy and Management.

Stocki, R., Prokopowicz, P. and Żmuda, G. (2008) Pełna partycypacja w zarządzaniu. Tajemnica sukcesu największych eksperymentów menedżerskich świata, Kraków: Oficyna Wolters Kluwer business.

Sztompka, P. (2007) Zaufanie fundament społeczeństwa, Kraków: Wydawnictwo Znak.

Yero, J.L. (2002) Teaching in Mind. How Teachers Thinking Shapes Education, Hamilton, Montana: MindFlight Publishing.

York-Barr, J., Sommers, W.A., Ghere, G.S. and Montie, J. (2001) Reflective Practice to Improve Schools. An Action Guide for Educators. Thousands Oaks, California: Corwin Press, Inc. 